\title{
Challenges for Bilingual education at the junior secondary level of education in Sri Lanka: Student and teacher perspectives
}

\section{Subhashinie Wijesundera*, Sakunthala Yatigammana, Prasad Sethunga}

Department of Education, Faculty of Arts, University of Peradeniya, Sri Lanka

\section{Abstract}

The purpose of this qualitative case study is to understand the challenges for implementing Bilingual Education (BE) at the junior secondary level of education in Sri Lanka from the perspective of students and teachers. Six bilingual teachers and 30 students from Grades 6 and 8 of a selected school participated in the study. Focus Group Interviews (FGI) with the students and semi-structured interviews with the teachers were used to generate data. It has emerged in the analysis that both teachers and students face many challenges and issues in teaching, learning and assessments in their classrooms mainly due to lack of adequate and appropriate physical and human resources and the lack of necessary support from school and other educational authorities. Teachers with limited experience and training in BE had to face many difficulties in teaching and assessment of students due to the lack of sufficientL2 proficiency among their learners. Students, in turn, face challenges in learning and assessments due to the lack of necessary basic skills in L2 and support from their teachers, peers and

*Correspondence should be addressed to Dr Subhashinie Wijesundera, Department of Education, Faculty of Arts, University of Peradeniya, Sri Lanka

Email: subhashinie.wijesundera@arts.pdn.ac.lk

https://orcid.org/0000-0002-6001-3597

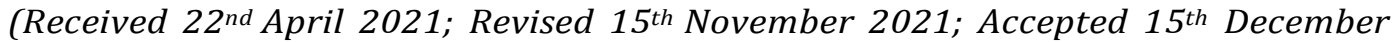
2021 (C) OUSL)

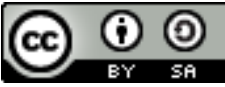

This article is published under the Creative Commons Attribution-Share Alike 4.0 International License_CC-BY$\underline{\mathrm{SA}}$ ). This license permits use, distribution and reproduction in any medium; provided it is licensed under the same terms and the original work is properly cited. 
home environments as well as self-learning skills. In conclusion, the authors argue that since BE is beneficial to both individuals and society, it needs to be expanded and further developed to enhance equity, inclusivity, and quality of education and capacity for lifelong learning among learners. Moreover, for successful implementation of BE, teachers and students should be adequately supported through a 'try level engagement' approach to education reforms.

Keywords: Bilingual education, Education reforms, Junior secondary level, Student and teacher perspectives, Teaching and learning

\section{Introduction}

A growing body of research indicates that Bilingual Education (BE) is beneficial to individuals as well as society. In his meta-analysis of the effectiveness of BE, Greene (1998) asserts that BE helps children to learn English and subject content. Wijesekera et al. (2019) based on a study conducted in bilingual classrooms in Sri Lanka argue that BE can be used by the teachers to promote more inclusive and 'supraethnic' identities among learners. Benson $(2002,2004)$ observes that BE in developing countries indicates encouraging development efforts in improving participation in primary education and learning processes. However, the teachers in those countries work in challenging contexts, which constitute undertrained and underpaid teachers, under-resourced schools and undernourished children (Benson, 2004). Studies conducted in Sri Lanka (Wickremagamage et al., 2010; Karunakaran, 2011; World Bank, 2011; Perera, 2014) also indicate comparable challenges for successful implementation of BE at the junior secondary level.

Bilingual Education (BE) has been introduced to the education system in Sri Lanka since 2002 under the 'National Amity Schools Project' (HRD/EQD/2002/12). Studies conducted on the implementation of BE in Sri Lankan schools indicate that the performances of bilingual students are generally high in all subjects at the GCE (O/L) examination (World Bank, 2011). However, the programme faces several challenges (NIE, 2007; Wickremagamage et al., 2009; World Bank, 2011; Karunakaran, 2011; Perera et al, 2014). These challenges could be summarized as follows:

- shortage of teachers in the government schools who are adequately competent to teach other subjects in the English medium and teacher educators competent to develop bilingual teachers;

- lack of a suitable Content and Language Integrated Learning (CLIL) model which is generally used in other countries; 
- lack of cooperation between ESL teachers and bilingual teachers in implementing BE in schools; and

- lack of specifically prepared textbooks for BE.

The above challenges need to be addressed at different levels of the education system by different authorities and actors. Although these challenges are identified at the macro level, the challenges faced by teachers, students, parents and principals at the school level have not been well understood in the Sri Lankan context. Therefore, the current study particularly focuses on understanding the challenges faced by teachers and students in bilingual classrooms. Following specific objectives have been set for this purpose:

1. to explore the challenges faced by the teachers in the teaching and learning process of bilingual classrooms in the particular school.

2 . to understand the problems and issues faced by the students in bilingual classrooms.

\section{Review of Literature}

\section{Bilingual Education in the Sri Lankan context}

Bilingual education in Sri Lanka in the current form is first introduced in 2002 through a circular issued by the MoE. According to the Circular, the main objective of the initiation of $\mathrm{BE}$ was to enhance social harmony and develop proficiency of students in Sinhala, Tamil and English while providing opportunities to study selected subjects in English medium starting from grade six onwards. The subjects were Science, Mathematics, Social studies and Health and Physical Education. Another objective of the introduction of $\mathrm{BE}$ was to overcome the lack of exposure to the English language which is considered a major obstacle to the skill development in English (Perera, 2014).

In 2008 by Circular No.2008/12 the principals were instructed to mix mono-medium and bi-medium students and specified the number of subjects that can be taught in the English language based on the available resources of each school. Through the above mentioned Circular MoE instructed the schools to offer 6 subjects which include Mathematics, Science, Health and Physical Education, Western Music, Geography and Life Competencies and Citizenship Education. The maximum number of subjects that can be selected from the above to study in the English medium is 5 (Circular No. 2008/12 ED/01/12/06/15/01 section 4.4).

In the Sri Lankan Teacher Development Manual issued by the NIE (2010, p.76) CLIL has been recognized as an effective instructional approach for BE in the Sri Lankan context. However, Perera et al. (2014) point out that Sri Lanka lacks a clearly defined bilingual framework and as a result, it is 
difficult to define the content standards, process standards and the role of stakeholders in BE. Nanayakkara (2015) also agrees that the policy of 'BE was planted but not grown' in Sri Lanka. According to (Perera, 2014) there was only 17.5 per cent of schools of the total number of Junior Secondary schools implementing $\mathrm{BE}$ in the country at the time. Highlighting the weaknesses of the current BE programme in Sri Lanka, Perera (2014) argues for the adaptation of a CLIL model to develop bilingualism in learners.

\section{Theoretical Framework}

$\mathrm{BE}$ is a common education approach used around the world. An estimated 60-75 per cent of the world's population is bilingual.

$\mathrm{BE}$ is defined by Anderson and Boyer as follows:

"BE is instruction in two languages and the use of those two languages as medium of instruction for any part, or all of the school curriculum" (Anderson, Boyer \& Southwest Educational Development Laboratory, 1970 cited in Pacific Policy Research Centre (2010).

According to the above definition, a bilingual programme must provide both content and delivery in two languages. A more recent definition by Cummins (2008) describes BE as follows:

"BE is the use of two (or more) languages of instruction at some point in a students' school career" (Cummins cited in Creese \& Blackledge, 2010: p.103).

The main purpose of $\mathrm{BE}$ is to achieve bilingualism among the students. Garcia (2009) distinguishes two categories of definitions of bilingualism concerning early and late scholars. Early scholars in the early period of the 1930s considered only native-like control of two languages as a sign of bilingualism. The later scholars in the period of the mid-1950s defined bilingualism in a broader sense. They considered minimum proficiency in two languages as a sign of bilingualism while someone who can alternate between the two languages was bilingual.

Garcia (2009) argued that although the concept of 'balanced bilingualism' is a widely accepted idea among educators it has long been recognized that such a form of bilingualism does not exist. Garcia emphasizes that the concept of bilingualism itself has been extended beyond the traditional "balanced" conception of the bicycle with two perfect wheels. Garcia further iterates that bilingualism is not like a bicycle with two balanced wheels and it is more like an "All-terrain vehicle":

"The wheels of this vehicle do not move in unison or the same direction, but 
extend and contract, flex and stretch, making possible, over highly uneven ground, movement forward that is bumpy and irregular but also sustained and effective" (Garcia, 2009: 44-45).

The metaphor used by Garcia implies that BE has clear goals to achieve while carefully moving through a complex and difficult terrain constituted with interacting variables of two languages, academic contents, pedagogic practices, teaching and learning materials, students and the teacher.

Research in language acquisition and education provides a theoretical basis for BE. According to the developmental interdependence theory (Cummins, 1979), the development of a second language is dependent upon a welldeveloped first language. Cummins further postulates in his thresholds theory that a child must obtain a certain level of proficiency in both native and second language to achieve successful bilingualism. Cummins focuses both on primary language development and academic achievement (California State Department of Education, 1981). In his Common Underlying Proficiency (CUP) model, Cummins distinguishes two types of skills acquired by the students in learning a language. They are: Basic Interpersonal Communicative Skills (BICS) and Cognitive Academic Language Proficiency (CALP). BICS comprise everyday language skills while CALP is required to understand linguistically and conceptually demanding material in academic content areas (Cummins, 1981). According to Cummins (1981) if children master their CALP in L1, then it is transferred to L2 since the language proficiency is the same across the languages.

Krashen (1984) evaluates five hypotheses of language acquisition and learning environments and claims that the key to language acquisition is the exposure to substantial amount of comprehensible input under optimal conditions. Krashen's monitor model of second language acquisition has been used for designing and implementing educational programmes for language-minority students.

\section{Pedagogical approaches and practices used in bilingual education}

According to Garcia (2009), BE combines three pedagogical approaches that are well known in language education:

1. agrammatical approach (Grammar- translation method)

2. acommunicative approach (Immersion instruction and Integrated Content-Based Instruction - ICBI)

3. acognitive approach (use two languages with greater flexibility, twoway BE programmes and CLIL programmes

CLIL is used in many countries as a pedagogic approach in BE. Coyle et al. (2010) define CLIL as "a dual-focused educational approach in which an 
additional language is used for the learning and teaching of both content and language (p.1)."

Research findings on the CLIL approach recommend it as a successful strategy to improve students' foreign language competence in bilingual contexts (Coyle, 2009; Harrop, 2012; Benegas, 2012). Coyle et al. (2010) report that in their study about $2 / 3$ of the learners reported a positive attitude towards their CLIL experiences and felt motivated to continue using the foreign language. However, she cautions that CLIL raises many issues as it solves. Therefore, it must not be seen as a 'solution' to improving learner motivation in modern languages but as a 'fertile ground for changing practice which is no longer motivating'.

By reviewing some of the latest evidence and considering the interaction between CLILs features and contextual factors Harrop (2012) evaluates CLILs potentials and limitations. Accordingly, Harrop infers that CLIL has the potential to develop a higher level of linguistic proficiency and heightened motivation in the learners, support learners of different abilities and provide unique opportunities to prepare them for global citizenship. According to Harrop (2012), a major limitation of the CLIL approach is the possibility of imbalanced linguistic development in learners that promotes receptive skills rather than productive skills.

Garcia (2009) proposes 'translanguaging' as a pedagogical practice which is introduced by Cen Williams that switches the language mode in bilingual classrooms. Creese \& Blackledge (2010) in their study conducted in Chinese and Gujarati community language schools in the UK describes translanguaging as a flexible approach to language teaching and learning. They highlight the importance of teaching bilingual children using bilingual instructional strategies, in which two or more languages are used alongside each other. They discuss how the translanguaging approach can be used effectively in situations where teachers and students construct and participate in a flexible bilingual pedagogy in assemblies and classrooms.

Pacific Policy Research Centre (2010) cites Howard et al (2007) to highlight five critical features of successful bilingual and immersion programmes that relate to pedagogy. These features include: promotion of positive interactions between teacher and learners; use of a variety of teaching techniques that respond to different learning styles; student-centered teaching and learning; use of cooperative learning strategies where students collaborate interdependently on common objective tasks and share experiences; and the use of cooperative learning strategies which are focused around a language task that facilitates the students sharing language knowledge (Pacific Policy Research Centre, 2010, p. 8).

In this review, the authors have defined BE and bilingualism and identified 
that bilingualism is one of the main purposes of BE. It was also discussed that according to Garcia, there is nothing called balanced bilingualism and the concept of bilingualism can be identified metaphorically as an all-terrain vehicle that moves along difficult terrain. Theoretical underpinnings of BE includes the concepts of CALP and BICS introduced by Cummins in his CUP model and the Monitor model of Krashen (1984). The authors have also discussed research on effective pedagogical practices used in $\mathrm{BE}$ and identified the strengths and limitations of such practices. Understandings developed through the above review provides an analytic framework for our data analysis and interpretation.

\section{Methodology}

A qualitative approach was used in this research. The data reported in this paper were generated during the process of a Collaborative Action Research (CAR) study conducted over nine months. A part of the data collected in the CAR is used in this descriptive case study that utilizes qualitative data generated through the interviews with teachers $(n=6)$ and Focus Group Interviews (FGI) with selected groups of students from Grade $6(n=18)$ and Grade $8(n=12)$. Since there were more than 6-8 students in each group we have used a specific strategy to collect the responses from all students (including the shy ones, silent ones etc.) in which, the students were first asked to write their responses in brief in the mother tongue or English with the question number on a blank paper given to them when a question was posed. After they finished writing the volunteers were asked to elaborate their answers orally to the whole group. Written responses were collected at the end while oral comments were electronically recorded during the FGI. Interviews with teachers were also recorded electronically and later transcribed verbatim.

Consent of the teachers and students for participation in the research was obtained at the beginning of the study and data were anonymised immediately after the collection to ensure ethical conduct of the study. Eight out of nine teachers who teach in the junior secondary grades (Grades 611 ) in the English medium had given their consent for participation in the study. Percentages and a graph were used to analyze quantifiable responses of the students and the constant comparative method (Merriam, 2009) was used in the analysis of qualitative data to identify categories, patterns and themes.

\section{Findings and Discussion}

The context of the school and the BE programme and the analysis of the challenges faced by the students and teachers are presented below. 


\section{The school and the BE programme}

The school is situated within Kandy municipal limits. The total student population is 1800 and there are 84 teachers. Classes are held from Grades 1-13 and the school belongs to the type 1C category with GCE Advanced Level classes in the Arts and Commerce streams. According to the principal and the teachers, the majority of students in the school are from the lower middle class and low-income families.

The school was started as a Roman Catholic missionary school in the year 1837 and the government took control in 1962 as per the Parliamentary Act of the takeover of private and grant-aided schools in 1960. The school layout appeared somewhat compact with single and two-storied buildings erected close to one another in a limited land area.

BE has been implemented in the school since 2006. At present 123 out of 852 students in the Grades 6-11 are in BE classes. According to the BE teachers, the majority of students in the bilingual classes belong to the lower middle class. Also, there are a few students who receive Grade 5 Scholarship Examination (G5SE) bursaries which are offered by the government for the students who excel in G5SE and belong to low-income families.

The junior secondary curriculum consists of six core subjects, i.e. Sinhala/Tamil, English, Mathematics, Science, Religion and History and three groups of optional subjects called basket subjects. Students offer 9 subjects for the GCE (Ordinary Level) examination. The school offers five prescribed subjects, i.e., Mathematics, Science, Health and Physical Education, Geography and Citizenship education in the both Sinhala and English media and are thus categorized under bilingual subjects. Students in Grade 6-11 are encouraged to follow the above subjects in the English medium. To become a student in the bilingual stream the students must follow at least one subject from the bilingual subjects listed above.

On average, about 135 students who complete primary education in this school enter Grade 6 of the same school. However, only a small proportion of students opt for $\mathrm{BE}$. Teachers reported that the parents seem reluctant to admit their children to BE class due to many reasons which include the fear of failure to achieve good results etc. Therefore, to recruit an adequate number of students to the bilingual classes, the school adopts the following procedure:

- conduct annual special awareness programmes for the parents of Grade 5 scholarship holders on the benefits of $\mathrm{BE}$ to motivate them to admit their children to Grade 6 bilingual class. These 
programmers succeeded in convincing almost all parents of Grade 5 scholarship holders to admit their children to BE class.

- recruit additional students for Grades 6 bilingual classes based on a selection test administered by the school.

- prevent of the newly admitted BE students from opting-out of bilingual subjects of their choice until they reach Grade 9.

On the one hand, the above procedure appears to be a tightly controlled process that exerts considerable pressure on the parents to admit their children to bilingual classes. On the other hand, it puts a lot of pressure as well as the responsibility on the school authorities and BE teachers to provide better learning opportunities for the BE students and enhance their achievements. The school and the bilingual teachers seem to actively advocate the governmental policy on bilingual education.

The school uses both subject specialist teachers and ESL teachers to teach bilingual subjects. The teachers have been trained to teach in bilingual classes by the MoE, NIE and the provincial and zonal education offices through different short-term in-service training programmes.

Five out of six teachers who participated in the study were ESL teachers turned bilingual teachers. Their total years of experience in teaching range from 11 years to 30 years while their years of experience in bilingual teaching range from 1-8 years. Three of them had postgraduate qualifications in education. The mathematics teacher did not have professional training in language teaching (See details in Table 1).

\section{Table 1.}

Qualifications and experience of the bilingual teachers

\begin{tabular}{|c|c|c|c|c|c|c|}
\hline 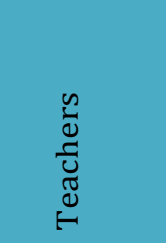 & 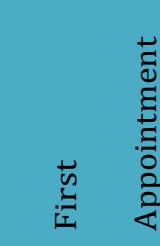 & 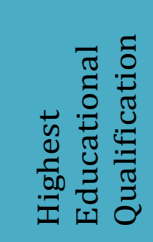 & 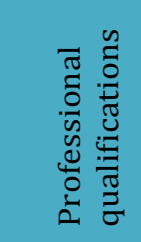 & 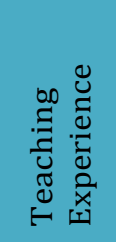 & 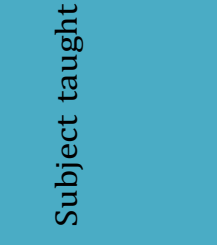 & 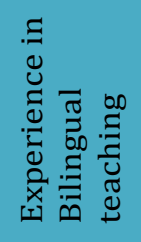 \\
\hline Teacher 1 & ESL & BA & PGDE* & 24 & $\begin{array}{c}\text { Civic } \\
\text { Education }\end{array}$ & 2 \\
\hline Teacher 2 & ESL & MA & PGDE & 16 & Geography & 8 \\
\hline Teacher 3 & ESL & $\begin{array}{l}\text { GCE } \\
(A / L)\end{array}$ & $\mathrm{TTC}^{* *}$ & 30 & Science & 2 \\
\hline Teacher 4 & ESL & MSc & PGDE & 15 & Science & 8 \\
\hline Teacher 5 & Mathemat & GCE & NDT*** & 17 & Mathematics & 3 \\
\hline
\end{tabular}




\begin{tabular}{ccccccc} 
& ics & (A/L) & & & & \\
Teacher 6 & ESL & $\begin{array}{c}\text { GCE } \\
(\mathrm{A} / \mathrm{L})\end{array}$ & NDT & 11 & Geography & 1 \\
\hline
\end{tabular}

Note: *Postgraduate Diploma in Education

**Trained Teacher Certificate

***National Diploma in Teaching

\section{Problems and challenges faced by the teachers}

Seven main categories of challenge emerged in the analysis of teacher responses.

1. Relatively small number of students in BE classroom

Teachers reported that the parents have been reluctant to admit their children to bilingual classes due to many reasons. Following comments that were made by parents and later reported by teachers in their interviews indicate some of these reasons:

"My child won't be able to get " $A$ " grades in $O / L$ if he studies in the English medium."

"Are there enough teachers to do bilingual subjects?"

(Interview data/teacher 1)

The parents seem to be worried about the possibility of their children achieving less than 9As at the GCE (O/L) examination which will make it difficult for them to admit their child to a more popular school to study for GCE (A/L). They also seem to be concerned about the possible resource constraints.

2. Dropping out of students from the BE programme from Grades 6-9

Teachers also highlighted the trend of students dropping out from grade 6 to $9 \mathrm{BE}$ classes due to their parents' concerns and misunderstanding:

"In grade 6, when the students get low marks, parents want to move their children to a monolingual class. The reason is these parents do not understand that a student takes some time to get familiar with the bilingual medium, which was a transformation from children's grade 1-5 learning medium of Sinhala." 


\section{Students' insufficient knowledge of English}

This was also identified as a major obstacle for teachers to meet the expected outcome of their lessons. The students' lack of sufficient vocabulary, knowledge on spelling and difficulties in answering questions in the target languages have been significant classroom realities. For instance, one teacher said:

"When we take the answer scripts we can see the blank spaces without answers. For example, during the last term test, there were some questions where students haven't even touched. We noted that when they are asked to provide answers in sentences or couple of sentences they never bothered to answer them".

(Interview data/teacher 4)

Teachers' views on students' knowledge of English were supported and further elaborated by the responses of students in the FGIs.

4. Additional administrative workload and other organizational barriers

Students and teachers both pointed out this issue. It was noted that assigning different responsibilities other than teaching by the school management is an issue for some of the bilingual teachers as it consumed a lot of teacher's teaching time:

"I was involved in the distribution of 'uniform materials' for students of the whole school during the past few weeks and I couldn't go to the classrooms some time."

(Interview data/teacher 2)

\section{Lack of permanent classrooms for BE}

During the interviews, all teachers highlighted this as a serious practical issue. One teacher articulated her view as follows:

"There is no particular place...I mean a classroom for BE students. Usually, 10-15 minutes we are spending searching for a place. Then we have only 25 minutes to give the content as well as to develop the language skills. On some days we have to conduct lessons under a tree. So how can we do a quality lesson?"

(Interview data/teacher 1)

6. Conflicting guidelines and circulars 
According to the data from teachers' interviews, ad hoc changes made by circulars and conflicting guidance provided by higher authorities from time to time posed serious challenges for teachers:

"Even the concepts are the same in science, there were some changes in the teaching methodologies from time to time. In the beginning, it was totally in one medium (English), later it was said that the students should know the mother tongue terms and not be much concerned about grammar, but now it is quite different in the CLIL methodology, the teacher should concentrate on both academic terms and accurate grammar."

(Interview data/teacher 4)

The teachers' view indicates the need to maintain consistency in BE policy.

7. Lack of support for students at home

Teachers also reported that most of the bilingual students in the school belong to the lower middle class whose parents were not English speakers:

"They don't know English. Most of them are unable to help the children at home."

(Interview data/teacher 3)

Teachers' view is further supported and elaborated by the students in their views on support from home environments.

\section{Challenges faced by the students}

According to the FGI data, almost all students (Grade 6 \& Grade 8) reported that they had one or more language problems concerning reading, writing, speaking and comprehension. Their problems emerged both in classroom learning as well as in the assessments/examinations. A comparison of the magnitude of the above problems faced by bilingual students in grades 6 and 8 is set out in Figure 1.

As shown in Figure 1, except for two problems, the magnitude of the problem for grade 6 students $(n=18)$ was always greater than that of the grade $8(n=12)$ students. The majority of students from both grades indicated that they had difficulty in understanding what the teacher explained in the bilingual lesson. A greater percentage of eighth-graders had this problem compared to the sixth-graders. The reported data indicates that grade 8 students were better in reading, remembering English words, as well as memorizing the meanings than the grade 6 students. Moreover, pronunciation was a great problem for grade 8 students compared to grade 
6 students.

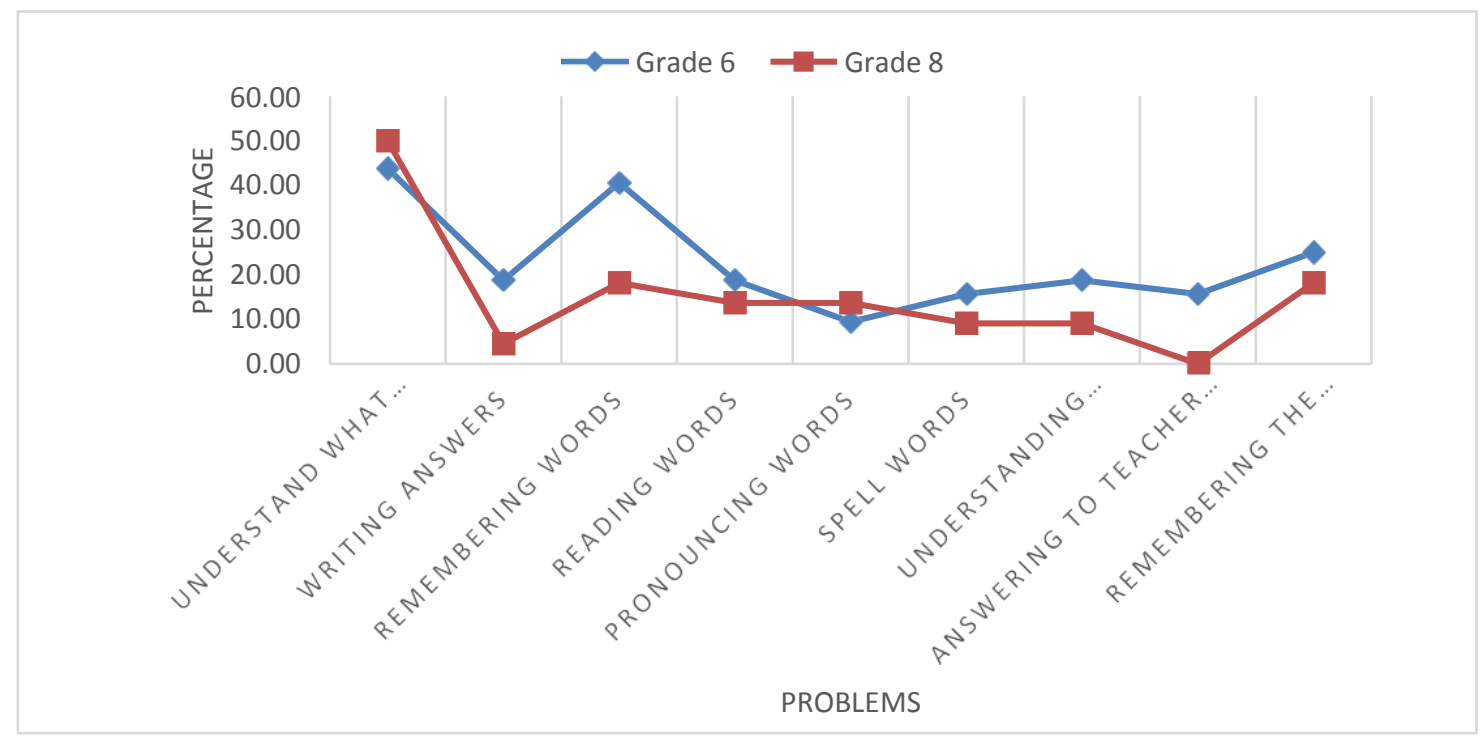

Figure 1: Language problems faced by students in Grade 6 and Grade 8

Students reported that these problems emerged both in classroom learning and in assessments/examinations. The following section elaborates the five categories of issues highlighted by the students in teaching, learning and assessments in their bilingual classrooms.

1. Insufficient second language (L2) skills

Among the problems that emerged in relation to insufficient L2 skills in classroom learning were:

- difficulty in understanding teacher explanations

- difficulty in remembering words and their meanings

- difficulty in reading

- difficulty in pronunciation

- difficulty in articulating answers to teachers' questions

- difficulty intaking down notes when the teacher dictates them

Insufficient L2 skills such as reading, comprehension, writing and speech and lack of an adequate vocabulary, spelling and the unavailability to use language learning resources such as dictionaries and modern technological tools seem to have affected students' learning. The situation implies a need to introduce appropriate resources for learning a second language and developing self-learning and self-directed learning (Zimmerman, 1990) 
skills among the students.

2. Inappropriate teaching strategies of the teachers

Students reported that during some of the lessons many of them had problems in understanding what the teacher explained in the classroom. Student comments are as follows:

"Our Health teacher uses difficult words in the lesson. He is not explaining some technical terms using simple words that we already know. Our civics teacher does that. When we come across two or three complex words while he is explaining we will not be able to understand the lesson."

(FGI /GR.8)

"When the teacher is not using Sinhala words in explaining lessons, I can't understand them"

$$
\text { (FGI /GR.6) }
$$

"Difficult to understand the subject as the teacher is not explaining all the terms. Even though I want to ask the meaning of the words during the class, I am scared to ask as the teacher always looks very serious"

(FGI /GR.8)

Students' difficulties seem to have been aggravated by the teacher's style of teaching and power relations between the teacher and the students. Apparently, there is little interaction and two-way communication between students and the teacher. Krashen's idea of the need to provide substantial amount of comprehensible input under optimal conditions to facilitate language acquisition or the Cummins' concepts of BICS and CALP do not seem to have received the attention of some teachers in the bilingual classrooms. The learning environment also did not seem to support student learning by providing opportunities to interact with the teacher and the peers and to use simple tools such as a dictionary and/or a thesaurus.

3. Difficulties in memorizing subject-specific terms

Memorizing content and subject-specific terms appear to have been difficult for some students:

"I try to remember the words but it is very difficult for me. When I hear some words in the classroom, I know some words are familiar to me. ...I mean I already tried to learn by heart those words. However, when I want them, the meaning of the word is not coming to my mind" 
(FGI /GR.8)

"I do not know the meaning of the words and I do not have a way to find the meaning of difficult words."

"I forget the meaning of the words."

(FGI /GR.6)

The above comments suggest that the students are used to rote learn the words and their meanings. The lack of student-centered pedagogic practices which promote meaningful learning rather than rote learning and the inability to use language learning resources in and outside the classrooms seem to aggravate this situation.

4. Problems of spelling and pronunciation

The students also seem to have problems of spelling and pronunciation:

"When the teacher reads the note, I can't take down them all... as the spellings of some words are not coming to my mind."

(FGI /GR.6)

"I do not know how to pronounce some words. So, when the teacher asks me to read it is very difficult. Always the teacher says that the way I pronounce is not correct."

(FGI /GR.6)

"The teacher is not pronouncing the words clearly. So, when I want to say that word I do not know how to pronounce it."

(FGI /GR.8)

Students' difficulties seem to be related to the teacher's way of teaching and providing guidance. Bilingual teachers seem to do their work in isolation and try to grapple with the issues that they face in classrooms individually. However, as pointed out by DuFour (2004) staff in schools need to focus on learning rather than teaching to improve student learning. They need to collaborate in groups to examine ways of helping students to learn better and hold them accountable for the results that lead to school improvement with commitment as effective professional learning communities (DuFour, 2004).

5.Lack of guidance and support at home 
Students also pointed out the difficulties that they encounter due to the lack of support and guidance at home for learning English.

"When I am doing homework or studying at home it is difficult to get the meaning of some words. No one is there to help me. I mean my mother and father do not know English."

$$
\text { (FGI/Gr.6) }
$$

Although this is the case for most of the students, one child pointed out:

"My father bought me a computer and I am using it to learn difficult terms etc."

(FGI/Gr.8)

The above students' response opens up the possibility of productive use of modern technology in and out of classrooms to support student learning in $\mathrm{BE}$ in this school.

\section{Discussion}

The above analysis indicates that $\mathrm{BE}$ is implemented at the school level amidst certain drawbacks. The lack of classroom facilities and other resources, the lack of adequate support and guidance for teachers from school and other levels of educational authorities to solve the context-based problems (for example lack of adequate permanent space to conduct bilingual classes) aggravate the situation. The challenges faced by teachers are comparable to those in developing countries where BE teachers work in challenging contexts, which are characterized by the presence of "undertrained and underpaid teachers, under-resourced schools and under-nourished children" (Benson, 2004).

Parental anxieties related to students' achievements in public examinations and their inability to provide appropriate support and guidance at home to their children also add to the complexities of the situation. Benson (2004) based on his studies conducted in Bolivia and Mozambique in primary schools' states that bilingual teachers have the challenge of teaching both communicative language skills in the 'exogenous' or old colonial language and curricular content in both at the same time. The teachers have to possess both bilingualism and bi-literacy for this purpose. Moreover, they have to fill the cultural and linguistic gap between home environment and school (Benson, 2004). Comparable situations prevail in the classrooms of the current study where the teachers have to work with inadequate physical resources and inadequate professional training and guidance in bilingual teaching while trying to address the issues of lack of support from children's home environments, parents and school authorities. 
According to Varghese (2010), unique characteristics of bilingual learners in different classroom settings require situated approaches to teaching and learning that require teachers to make choices and have specific understandings about their profession. The current study revealed the unique nature of the learners in this specific context and the dilemmas faced by the teachers in teaching, learning and assessment of the students. The study findings also implicate the need to provide adequate support by the peers, principals, and officers at different levels of education administration and the parents for the teachers to adapt their teaching according to the specific needs of students. To provide this kind of support to teachers it may be necessary to develop professional learning communities (DuFour, 2004) comprising teachers and other educational professionals who work collaboratively to enhance student learning in BE.

At the macro level, education authorities could also pay attention to providing additional curricular materials for the students studying in the bilingual mode to encourage self-learning and self-regulated learning (Zimmerman, 1990) to enhance their English language proficiency as well as content mastery.

It has also emerged in the current study that the ESL teachers are assigned to teach subjects for which they are not trained in the bilingual classrooms. This situation analyzed in previous studies (NEC, 2016; Perera, 2014). NEC (2016) recommends that when the need arises to employ an ESL teacher who has nonspecialized in the content area, such teachers should be encouraged to work with the regular subject teacher in planning lessons and assessing students.

Teachers were also of the view that students' lack of exposure to English at the primary school level made their task more difficult. NEC (2016) pays attention to this issue and recommends extending the current practice of implementing Activity Based Oral English (ABOE) from Grade 3 to Grade 1 onwards together with the second language (Sinhala for Tamil students and Tamil for Sinhala students). However, it is advisable to provide adequate training on the use of activity-based English and second language teaching for the primary teachers before the launching of this kind of programme and to provide ongoing support throughout the implementation. The idea of 'tri-level engagement' (Fullan, 2007) which advocates collaborative action by the education authorities (Central and Provincial levels), schools and teachers at the classroom level to improve students' learning is applicable here.

\section{Conclusion}

Although this study is limited to a single school and to the experiences of its BE teachers and students the above analysis suggests that teaching and 
learning in bilingual classrooms could be a great challenge for both teachers and students in this kind of under-resourced schools where students come from underprivileged families. Students' lack of necessary basic skills in the English language due to lack of exposure toL2 during primary school level and the inappropriate pedagogical practices used by the BE teachers appear to be a major barrier for successful BE in this particular school. In this context, the use of English as the medium of instruction in bilingual classrooms is quite problematic. Current practices need to be revised to include strategies such as the gradual introduction of English medium instructions. It may be useful to encourage teachers through teacher education and In-service training programmes to use more flexible approaches such as translanguaging (Garcia \& Lin, 2017; Creese \& Blackledge, 2010) in teaching and learning, student-centred teaching and an appropriate CLIL model by providing adequate theoretical understanding and practical strategies to flexibly adapt them in different classroom situations.

Bilingual education is beneficial to the individual as well as the society and therefore the authors argue that it needs to be further expanded and developed in Sri Lanka to enhance the quality, equity, inclusivity and to promote lifelong learning which is highlighted in the Sustainable Development Goal (SGD)-4 relevant to education. To improve the current situation of BE in Sri Lanka it is necessary to provide adequate training, guidance, and necessary resources as well as support for the BE teachers by the school and other relevant authorities. Developing professional learning communities (DuFour, 2004) comprising collaborating teachers in schools and other professionals/officers who are supposed to support teachers at the school level will also be useful to improve teaching-learning and students' achievements. To facilitate that kind of involvement of provincial/zonal and school level authorities and teachers the MoE and the NIE have to adopt a participatory approach or 'tri-level engagement' where mutual interaction and support for change occur among three levels of school and classroom, provincial, and Central (MoE and NIE) as suggested by Fullan (2007) in reforming education rather than using a top-down approach.

\section{Acknowledgement}

The study was conducted under the English Language Teaching Research Partnership (ELTRP) award 2015/2016 of the British Council, Sri Lanka. We deeply appreciate the contribution of the bilingual teachers and students in the particular school who participated in the study and the assistance provided by Priyani Panditharathne of K/Peradeniya Central College, at the initial stage of this study. 


\section{References}

Benegas, D. (2012). CLIL teacher development: Challenges and experiences. Latin American journal of content and language integrated learning, 5 (1), 46-56.

DOI:10.5294/laclil.2012.5.1.4

Benson, C. (2002). Real and Potential Benefits of Bilingual Programmes in Developing Countries. International Journal of Bilingual Education and Bilingualism, 5(6), 303-317.

DOI: $10.1080 / 13670050208667764$

Benson, C. (2004). Do we expect too much of bilingual teachers? Bilingual teaching in developing countries. Bilingual Education and Bilingualism, 7(2\&3), 204-221.

DOI: $10.1080 / 13670050408667809$

Creese, A. \& Blackledge, A. (2010). Translanguaging in the Bilingual Classroom: A Pedagogy for Learning and Teaching? The Modern Language Journal, 94(1), 103-115. Retrieved April 20, 2021, from http://www.jstor.org/stable/25612290

Coyle, D. (2009). Investigating Student Gains: Content and Language Integrated Learning, ITALIC Research Report. Aberdeen: University of Aberdeen.

http://www.abdn.ac.uk/italic

Coyle, Do, Hood, Philip, Marsh, David (2010). Content and Language Integrated Learning. Cambridge: Cambridge University Press I.C.

Cummins, J. (1979). Linguistic Interdependence and the Educational Development of Bilingual Children. Review of Educational Research, $49,222-251$.

https://doi.org/10.3102/00346543049002222

Cummins, J. (1980). The Entry and Exit Fallacy in Bilingual Education. NABE Journal, 4, 25-60. https://doi.org/10.1080/08855072.1980.10668382

Cummins, J. (1981). Empirical and theoretical underpinnings of bilingual education. The Journal of Education, 163(1), 16-29. http://www.jstor.org/stable/42772934

Cummins, J. \& Honberger, N. (2008). Encyclopedia of language and education (second edition). Bilingual Education, 5, 1-16.

DuFour, R. (2004). Schools as learning communities: What is a learning 
community? Education Leadership, 61(8), 6-11.

Flores, B. B. (2001). Bilingual Education Teachers' Beliefs and Their Relation to Self-Reported Practices, Bilingual Research Journal, 25, 3, 275-299.

DOI: $10.1080 / 15235882.2001 .10162795$

Fullan, M. (2007). Change Theory as a Force for School Improvement. In: Burger J.M., Webber C.F., Klinck P. (eds) Intelligent Leadership. Studies in Educational Leadership, vol 6. Springer, Dordrecht. https://doi.org/10.1007/978-1-4020-6022-9_3

Garcia, O. (2009). Bilingual education in the 21st century: A global perspective. New York: Wiley.

García, O. \& Lin, A. M. Y. (2017). Translanguaging in Bilingual Education. In: García O., Lin A., May S. (eds) Bilingual and Multilingual Education. Encyclopedia of Language and Education (3rd ed.). Springer, Cham.117-130. https://doi.org/10.1007/978-3-319-02258-1_9

Greene, J. A. (1998). Meta-analysis of the effectiveness of the bilingual education. Austin: University of Texas.

Harrop, E. (2012). Content and language integrated Learning (CLIL): Limitations and possibilities. Encuentron, 21, 57-70 and 21, 55-70. https://eric.ed.gov/?id=ED539731.

Karunakaran, T. (2011). Bilingual Education and its Implications in Sri Lanka. Contemporary Discourse, 2(1), 19-25.

Krashen, S. D. (1984). Bilingual Education and Second Language Acquisition Theory. In California State Department of Education. Schooling and minority students: A theoretical framework. Sacramento, Office of Bilingual and Bicultural Education, California State Department of Education, 63-91. ED 249773.

Merriam, S. B. (2009). Qualitative Research: a guide to design and implementation. San Francisco: Jossey-Bass.Nanayakkara, P. (2015). Critical Analysis of the Bilingual education Policy in Sri Lanka. Educational Perspectives, 4(2), 15-32.

National Institute of Education. (2010). Teacher development manual-2. Maharagama: Cell of language Coordination, NIE.

National Education Commission. (2016). Study on Medium of Instruction, National and International Languages in General Education in Sri 
Lanka Research Series (2014) - No. 09. Nugegoda, Sri Lanka, National Education Commission.

Pacific Policy Research Center. (2010). Successful Bilingual and Immersion Education Models/Programs. Honolulu, Kamehameha Schools, Research \& Evaluation Division.

Perera, M. K. (2014). An attempt to develop bilingualism in Sri Lanka through content and language integrated learning (CLIL). International Journal of Arts \& sciences, 7 (3), 107-116.

Varghese, M. (2004). Professional Development for Bilingual Teachers in the United States: A Site for Articulating and Contesting Professional Roles. International Journal of Bilingual Education and Bilingualism, 7, 2-3, 222-237.

DOI: $10.1080 / 13670050408667810$

Wickramagamage, C., Sethunga, P. \& Kalugampitiya, M. (2010). The pursuit of equity and excellence in English education through English medium/Bilingual education in the Sri Lankan education system: Effective strategy to meet desired end? Unpublished Final research report, RG/2008/19/A, University of Peradeniya, Sri Lanka.

Wijesekera, H. D., Alford, J. \& Guanglun, M. M. (2019). Forging inclusive practice in ethnically-segregated school systems: lessons from one multiethnic, bilingual education classroom in Sri Lanka, International Journal of Inclusive Education, 23,1 and 23-41, DOI: $10.1080 / 13603116.2018 .1514730$

World Bank. (2011). Transforming School Education in Sri Lanka: From cut-stones to polished jewels, Colombo: The World Bank Colombo Office.

Zimmerman, B. J. (1990). Self-regulated learning and academic achievement: An overview. Educational Psychologist, 25(1), 3-17. DOI: $10.1207 / s 15326985 e p 2501 \_2$ 